\title{
How Traditional Tribal Perspectives Influence Ecosystem Restoration
}

Jonathan W. Long, Frank K. Lake, Ron W. Goode, and Benrita Mae Burnette ${ }^{4}$

${ }^{1}$ USDA Forest Service Pacific Southwest Research Station, Davis, California, USA.

${ }^{2}$ USDA Forest Service Pacific Southwest Research Station, Arcata, California, USA.

${ }^{3}$ North Fork Mono Tribe, Clovis, California, USA.

${ }^{4}$ Member of White Mountain Apache Tribe, Whiteriver, Arizona, USA.

\section{Abstract}

The hundreds of Indigenous tribes in the United States harbor diverse perspectives about the natural world, yet they share many views that are important for ecosystem restoration efforts. This paper features examples of how such views have guided ecosystem restoration through partnerships between tribal communities and the U.S. Forest Service in the western United States. Traditional perspectives have influenced restoration by deepening the understanding of reference conditions, expanding consideration of system dynamics, and guiding treatment based upon ethical principles and beliefs. More holistic perspectives may enhance restoration success by encouraging positive psychological and social effects that help sustain community efforts. Guided by traditional perspectives, restoration activities can reveal evidence of past human engagement with the land, which further illustrates the need and opportunity for restoration. Traditional perspectives can encourage more integrative, ethical, and self-reinforcing restoration that will benefit present-day tribal and non-tribal com-

(C) Jonathan W. Long et al. 2020; Published by Mary Ann Liebert, Inc. This Open Access article is distributed under the terms of the Creative Commons License (http://creativecommons.org/licenses/by/4.0), which permits unrestricted use, distribution, and reproduction in any medium, provided the original work is properly cited. munities. Key Words: Ecological restoration-Ethics-Traditional ecological knowledge-Native Americans-Cultural values.

\section{Introduction}

he hundreds of Indigenous tribes in the United States harbor diverse, accumulated knowledge about caring for the lands in which they have lived. To explain how traditional ecological wisdom can inform current science and efforts to care for the Earth, we drew upon our experience working among tribal communities and the US Forest Service in the western part of the United States, particularly in Ndee (Western Apache) territory in Arizona, Nium (Western Mono) territory in the Sierra Nevada of California, and territories of the Karuk, Yurok, and Hoopa Tribes in northwestern California. We have worked on collaborative projects that brought together Western scientific approaches and tribal traditional ecological knowledge (TEK). We highlight examples from these experiences where insights from traditional practitioners influenced ecological restoration efforts in ways that depart from the tendencies of conventional Western management and science. We focus on commonalities across several examples, but we also note that different tribal communities may have different views on specific restoration challenges.

Federal and state agencies engage with tribes and consider traditional knowledge to uphold moral and legal obligations and to achieve better restoration outcomes. For example, the U.S. Forest Service's "roadmap" for tribal engagement recognizes both the various legal requirements to engage with tribes and the benefits of such engagement for developing new strategies to sustain ecosystems and human communities (USDA Forest Service, 2015). The agency's current land management planning rule requires decision-makers to request information about tribal ecological knowledge and land ethics as part of participation and consultation with tribes (Long, Lake, Lynn, \& Viles, 2018). Academic research has explored how Indigenous traditions, norms, technologies, and conservation practices have promoted sustainable harvest (Berkes \& Turner, 2006) 


\section{LONG ET AL.}

and developed sophisticated coupled socioecological systems, ranging from cultivated wetlands to fire-tended forests (Cajete, 2000; Rossier \& Lake, 2014). Responding in part to the emerging interest in TEK within academic research and agency policies, native researcher Deborah McGregor (2005) has noted that the term can be problematic for Indigenous peoples because it describes an academic field often dominated by non-Indigenous persons and because definitions of TEK may not translate well to Indigenous understandings. Our collaborations have had to contend with related tensions about how (and by whom) traditional knowledge is defined, safeguarded, and appropriately applied. Such tensions are often exacerbated by the fact that research efforts favor English (and associated "scientific language" such as botanical names) as well as written publications rather than oral traditions. Our collaborations have pushed back against these tendencies by referring to native names of places and organisms, as well as emphasizing hands-on-restoration, conversation, and observation with youth and elders of different genders at culturally important sites.

\section{Deepening the Understanding of Restoration}

Ecological restoration has been defined as "the process of assisting the recovery of an ecosystem that has been degraded, damaged, or destroyed" (Society for Ecological Restoration International Science \& Policy Working Group, 2004, p. 3). Many collaborative projects with tribes have embraced the broader concept of ecocultural restoration that considers humans to be integral to the natural world (Long et al., 2018). This perspective acknowledges that nonIndigenous colonial systems of management have disrupted ecosystems and social systems, and that restoration of ecosystems must consider the capacity of tribes to continue to sustain themselves as they did prior to colonization (Lake, Parrotta, Giardina, DavidsonHunt, \& Uprety, 2018). Traditional perspectives and TEK provide insights into hidden or lost ecological diversity and relationships that tribes have had with their environments. While agency perspectives sometimes focus on recent conditions that can be readily quantified, traditional knowledge often affords a deeper retrospective view that can enhance restoration by describing system dynamics and conditions prior to ecosystem degradation (Guerrero-Gatica, Aliste, Et Simonetti, 2019).

\section{Examples of understanding past conditions on White Mountain} Apache tribal lands

The White Mountain Apache Tribe has decades of distinguished history in restoring its tribal lands in Arizona (Tomblin, 2010). TEK has guided some of those efforts. For example, upon listening to a radio broadcast by Mae Burnette (one of the authors) on the tribe's restoration projects, an elder called to recount a story (in the Apache language) that described how willows once grew at one of the sites that was mentioned. Practitioners then located a remnant willow at the site, which led to efforts to protect and outplant it. Maps and stories from elders similarly describe places where culturally and ecologically important wetland plants, such as common reed (Tlok'aa) and yerba mansa, once grew but have since disappeared (Long, Tecle, \& Burnette, 2003; Pilsk \&t Cassa, 2005). Elders also recalled memories of rich blue colors at springs that had since taken on gray and muddled hues, which suggested how the aesthetic and biochemical quality of those sites had changed (Long \& Endfield, 2000). Such observations have enriched the understanding of targets for restoration.

\section{Understanding System Dynamics}

Traditional ecological knowledge (TEK) tends to consider interrelationships among species, and it often reveals deep understanding of system dynamics (Chisholm Hatfield, Marino, Whyte, Dello, \& Mote, 2018). Scientist and traditional practitioner Robin Wall Kimmerer has emphasized how traditional perspectives promote a more unified understanding of ecosystems, especially the interacting relationships among water, plants, and animals (Kimmerer, 2013). As an example, the Karuk Tribe's climate adaptation plan notes that "TEK considerations do not involve single species management, but whole landscape improvement for the collective benefit of the people, the animals, and the plants" (Karuk Tribe, 2019, p. 53). The tribe's plan considers 22 plants and animals as cultural indicators of important relationships and responsibilities for management actions. Traditional perspectives also highlight the importance of fire in shaping ecosystem function and diversity (Anderson, 2018; Eriksen Et Hankins, 2014; Klimaszewski-Patterson \& Mensing, 2016). In recent years, traditional knowledge of fire effects has informed restoration and research among both the Karuk Tribe (Halpern, 2016) and the North Fork Mono Tribe (Long, Goode, Gutteriez, Lackey, \& Anderson, 2017).

In addition to helping with understanding how systems operate, traditional learning systems encourage understanding of people's responsibilities to maintain those systems, often by emphasizing the concept of reciprocity (Casagrande \& Vasquez, 2009). These moral values spring not simply from recognizing people's dependence on the natural world but rather from a deeper notion of unity with it. As one member of the Penobscot Nation has said, "the river is us; the river is in our veins.... If the rivers are the lifeblood of our Mother 


\section{TRADITIONAL PERSPECTIVES INFLUENCE RESTORATION}

and they become contaminated, then the same happens to us" (C. A. Fox et al., 2017, p. 528). Or as one Hopi Tribal leader has explained, "This is the place that made us" (Casagrande \& Vasquez, 2009, p. 196). Leslie Marmon Silko has noted that the term "landscape" tends to reduce human beings to mere viewers when actually "The land, the sky, and all that is within them-the landscapeincludes human beings" (Silko, 1987, p. 266). Accordingly, many tribal perspectives may favor terms such as "homeland" over "landscape" when describing the aims of their restoration efforts.

Leaders in the academic field of ecological restoration have championed the concept of "holistic," "unified," or "integrated" restoration, often while citing examples that involved Indigenous communities. For example, Clewell and Aronson (2006) urged the adoption of more "unified approaches" for ecological restoration that would renew "the nexus between nature and culture" (p. 424). They argued that many agency-led restoration efforts instead have focused on narrower ecological objectives such as reducing erosion, improving wildlife habitat, and protecting endangered species. More recently, Aronson, Blignaut, and Aronson (2017) characterized ecological restoration as "holistic" when it seeks "not only to help impaired ecosystems recover lost complexity, functionality, structure, and 'health,' but also to increase their social, economic, and cultural desirability in the eyes of local residents and other stakeholders" (p. 189). Higgs (2005) similarly called for an "integrated restoration" that melds the natural and human sciences and humanities, giving an example of ecological and cultural restoration by the Songhees First Nation in Canada.

Traditional learning systems instill a lifelong pursuit of knowledge. Tribal practitioners emphasize that while they do not live entirely on the land as they once did, they continue to live in and around the land to maintain their livelihoods, learning, and teaching. Tribes are using and adapting cultural indicators as a part of their efforts, as Bill Tripp from the Karuk Tribe has noted, "We need to get out there, take actions and observe. We don't need to know everything now in order to get it right" (Karuk Tribe, 2019, p. 59). That idea has been incorporated into land management and ecological restoration under the name "adaptive management" (Berkes, Colding, \& Folke, 2000).

Traditional perspectives often contrast with the short-term nature of graduate research at universities, agency-funded annual monitoring programs, and grant-funded restoration projects. Adoption of adaptive management has been stymied by agencies' focus on monitoring select system attributes to answer narrow questions concerning implementation and short-term outcomes (Bash \& Ryan, 2002). Much monitoring and research sponsored by agencies has targeted rare and endangered species rather than overall biodiversity. Over two decades ago, the federal government's Northwest Forest Management Plan called for increased investments in biodiversity monitoring, socioeconomic monitoring, and adaptive management, but since then, those elements were largely unrealized or discontinued due to a lack of funding support (Spies et al., 2019). Narrowing the scope of monitoring reduces costs but may risk failing to understand changes in broader diversity and long-term dynamics. Because Western scientists and land managers detect what is visible during infrequent surveys, they may not notice subtle effects, such as effects of different kinds of wildlife that frequent the areas being treated.

Similarly reflecting a short-term focus, management agencies have often leaned toward conservative protection measures, such as designating no-management zones as habitat for rare or declining species such as salmon, owls, and fishers, rather than conducting more active restoration in and around those areas to increase resilience to future disturbances (Spies et al., 2019). In contrast, tribes often consider active restoration important for both eco-cultural revitalization and conservation of those species (Aldern \& Goode, 2014; Long et al., 2017; Willette, Norgaard, Reed, \& Tribe, 2015).

Traditional perspectives may also differ from the emphasis of Western science on classifying phenomena into distinct and onedimensional categories; as explained by Vine Deloria Jr., "Tribal knowledge systematically mixes facts and experiences that Western science would separate by artificial categories" (Deloria \& Deloria, 1999, p. 67). For example, Western fire and air quality science often categorizes smoke as a pollutant and therefore something to avoid and minimize, rather than an important ecological element. However, tribal perspectives acknowledge smoke as an indispensable part of the ecosystem, serving like "medicine" for ecosystems by encouraging new growth of plants and production of acorns while reducing pests (Aldern \& Goode, 2014). Such traditional views have encouraged research to understand how smoke from fires could benefit fish populations by ameliorating high summer temperatures in the Klamath River (David, Asarian, \& Lake, 2018). The concept of "ecosystem services," which is increasingly embedded in agency decisions, highlights ways in which human communities are connected to ecosystems. However, some tribes may object to the implication that only the flow of benefits from nature to humans really matters and that such benefits should be quantified in monetary terms (Aldern \&t Goode, 2014; Raymond et al., 2013; Winthrop, 2014). An alternative framework of "stewardship" reverses the concept of ecosystem services by focusing on the obligations of humans to care for nature (Winthrop, 2014). 


\section{LONG ET AL.}

\section{Understanding Worldviews and Ethical Considerations}

In addition to deepening the understanding of how ecosystems operate, traditional knowledge suggests how humans should behave toward the nonhuman elements of those systems and why it is important to treat them with respect. Traditional perspectives in environmental ethics are important not only for respecting the values of diverse societies; but in many cases, these traditional cultural values have important ramifications for management. Intimate interactions with plants and animals over countless generations supported the development and transmission of practices, principles, and worldviews that can guide restoration (Anderson, 2005).

\section{Interconnectedness and kincentricity}

Worldviews of tribal traditional peoples are often rooted in "kincentricity," with origin stories that depict humans as having been able to converse with "four-legged" animals, "winged animals," and other nonhuman creatures since their emergence (Aldern \& Goode, 2014; Rogers-Martinez, 1992; Salmón, 2000). Tribes inform their present-day restoration efforts based upon inherited belief systems; for example, "the Nium still consider these animals, plants, water, and wind to be relatives and full citizens in their community" (Aldern \& Goode, 2014, p. 29). Bill Tripp of the Karuk Tribe has described how such beliefs have informed current efforts to restore fire: "We learned to manage from the animals. If you listen to the animals, they are asking for this good fire to come back" (Terence, 2016). Reflecting the principle of kincentricity, guidance for climate change adaptation recently developed by an Indigenous team has referred to "relatives" and "beings" (Tribal Adaptation Menu Team, 2019) in contexts where agency-led guidance has used the words "species" or "resources" (Swanston et al., 2016).

The worldview that all living things are connected through living communities is expressed through norms that consider impacts on entire ecosystem networks. Traditional practices do often promote species that have high utilitarian value as food, medicine, and materials that help people live, but they also consider how those food webs support nonhuman inhabitants (Aldern \& Goode, 2014). Tribal practitioners emphasize concerns for species that do not yield such tangible benefits (Rogers-Martinez, 1992). For example, the Karuk Tribe's climate plan (2019) considers animals such as giant salamander and garter snake that are recognized in stories and ceremonies even though they are not harvested. Another example is the California condor, which tribes such as the Yurok Tribe (2019) want to reintroduce because of its importance in tribal legends and ceremonies as well as in regional food webs.
Traditional tribal perspectives commonly regard waterbodies, rocks, and other places as alive and therefore worthy of thoughtful and respectful care (Bang, Warren, Rosebery, \&t Medin, 2012). Indeed, research has found that native students regard this view as one of the most prominent differences between the teaching of elders and those of typical Western scientists (Bang \& Medin, 2010). Mae Burnette has described her vision for restoration as rooted in the belief that springs need to "breathe" (Long et al., 2003). And as Bill Tripp has explained in a Karuk tribal plan, "In our worldview, cultural resources have a life, as do the people using them. Each life deserves consideration when planning projects" (Karuk Tribe, 2019, p. 57). The concept that the natural world is imbued with life and our home, rather than merely a source of services, reinforces the idea that restoration is a way toward proper living rather than simply another tool to serve humans.

The following two examples of fire and water restoration illustrate how these perspectives have encouraged rethinking of conventional ecosystem restoration approaches.

\section{Example: Cultural burning to restore diverse systems}

Tribes throughout much of the United States have advocated using traditional burning practices to restore degraded ecosystems, especially to restore hardwood groves, prairies, meadows, and open forests. Agency-led prescribed burns have developed with insights from traditional burning practices, but they often have a narrower focus on reducing the risk of more dangerous wildfires. Tribes plan and conduct cultural burns to promote a range of desired outcomes based upon traditional knowledge about plant associations, weather, topography, among other attributes (Karuk Tribe, 2019). For example, the location of burns is shifted based upon when birds return to particular areas to nest (Karuk Tribe, 2019). While the Karuk Tribe has strongly advocated for restoring fire, tribal elders have passed down beliefs that burns conducted between April and mid-June, which is demarcated by the disappearance of the Pleiades star cluster from the night sky, could be harmful to plants and animals (Halpern, 2016; Karuk Tribe, 2019). Recent research has shown that there can be risk to fisher pups from prescribed fires during several weeks in the spring, due to the potential for carbon monoxide to accumulate in den trees (Thompson \& Purcell, 2016). Traditional tribal perspectives recognize that fire can have positive or negative effects depending on complex factors, but they emphasize that fire often benefits species of concern including owls, fishers, and butterflies over the long term by promoting favorable dwelling structures and food sources (Aldern \& Goode, 2014; Long \& Lake, 2018). Even though tribes and agencies broadly support using fire in restoration, the 


\section{TRADITIONAL PERSPECTIVES INFLUENCE RESTORATION}

complex interactions and competing values illustrate why it is important to broadly consider treatments when confronting novel challenges.

Restoration efforts themselves can enrich the understanding of ecocultural restoration opportunities. For example, North Fork Mono Tribal Chair Ron Goode (one of the authors) has explained that burns commonly reveal a site or artifacts that were not seen before (Goode, 2013) (Fig. 1). While both agency personnel and tribal members recognize that there are risks that fires will reveal or damage artifacts, restoration may advance by making that interwoven history and patterning of a place more visible, especially to young people. Cultural burns and wildfires have triggered the reemergence of some plants, like tobacco, that have strong cultural affiliations (Aldern \& Goode, 2014). Therefore, restoration activities reveal the coupled nature of social-ecological systems in ways that further inform and motivate additional activities (Long \& Lake, 2018). As tribes expand these practices into additional sites and even into different ecological communities, they continue to learn how to restore social-ecological systems in an ever-changing world.

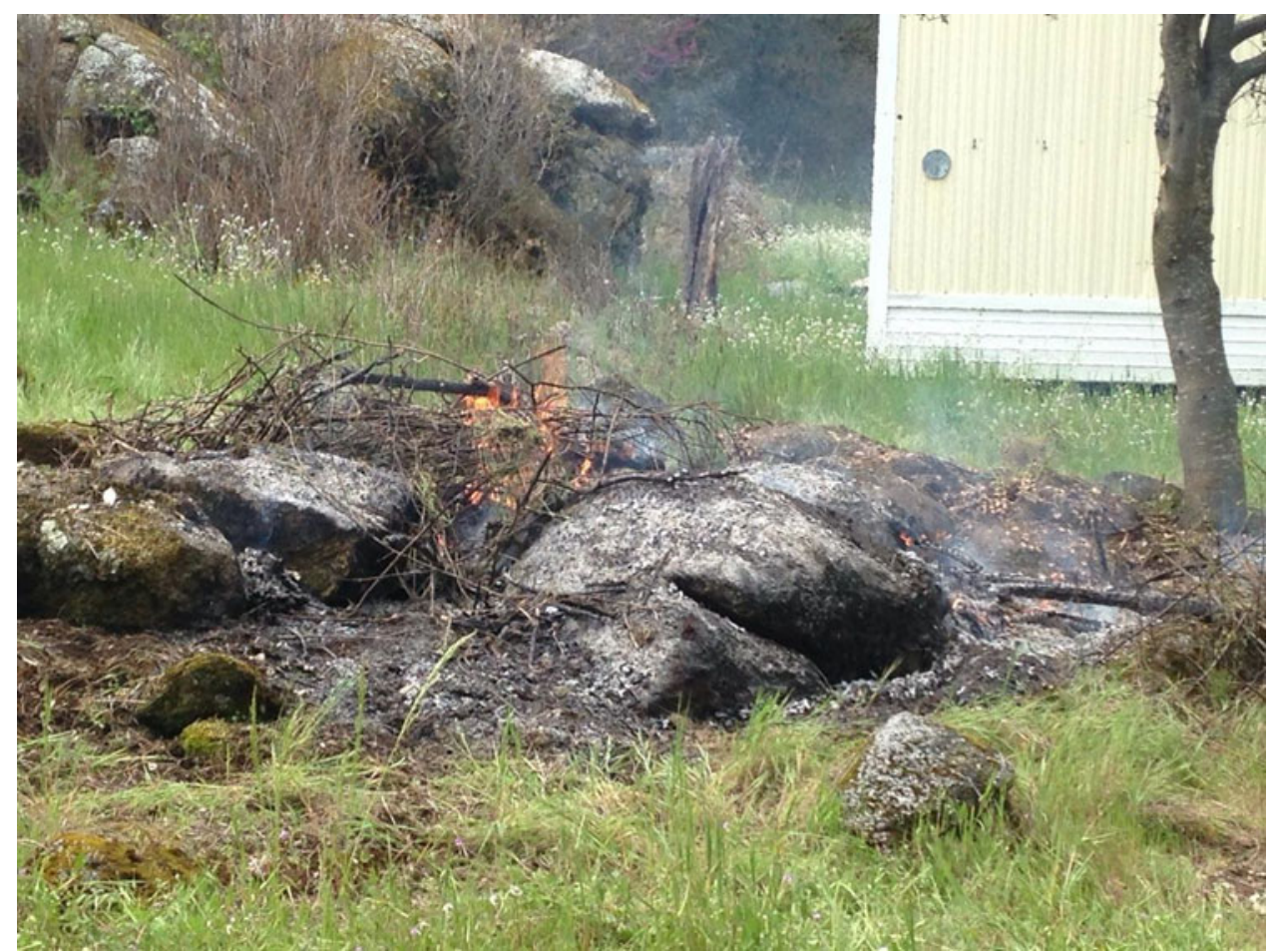

Fig. 1. A cultural burn at this Mariposa site by the North Fork Mono Tribe revealed tools and other evidence of past habitation by Native Americans (photo by Ron W. Goode).

\section{Example: Holistic meadow restoration}

At several meadow sites in the central Sierra Nevada, the North Fork Mono Tribe has partnered with the Forest Service to undertake restoration treatments. The Tribe has conducted monitoring by recording all the species that they have observed at the meadows since they began work there, adding new species of all kinds to their list every year. From a Western research perspective, it is difficult to evaluate cause-and-effect relationships from such data. However, this approach is useful in documenting species that are likely to be missed in plot or transect-based designs that constrain sampling in space and time and to specific kinds of plants or animals. Ron Goode explains that they have taken this approach because, "if you do not know which of your relatives lives out there, how do you know who you are affecting when you burn or do other treatments?"

As another example of this broad view, Ron Goode was concerned that native wildflowers would not recover quickly enough following meadow restoration treatments to sustain insects through the winter. Therefore, he called for leaving some of the remaining bull thistle plants as a food source; meanwhile a local Forest Service specialist expressed a desire to remove all of them because they are an invasive, non-native species. However, a recent study rests more comfortably with the tribal leader's perspective, as it highlighted that leaving residual non-native floral resources can be important to sustain native butterflies until the native floral community recovers (Russo, Nichol, \&t Shea, 2016).

Traditional practitioners, including Ron Goode and Mae Burnette, broadly conceive of meadow and spring restoration using terms such as "bringing back the water" to describe a reflourishing of these places. Their broad vision sometimes contrasts with narrower agency-led efforts that focus on stemming further damage. For example, staff on the Sierra National Forest characterized restoration as placing rocks below active headcuts to arrest further degradation of a meadow (Fig. 2), while the North Fork Mono Tribe proposed broader efforts to restore the already incised channels and to treat tree 


\section{LONG ET AL.}

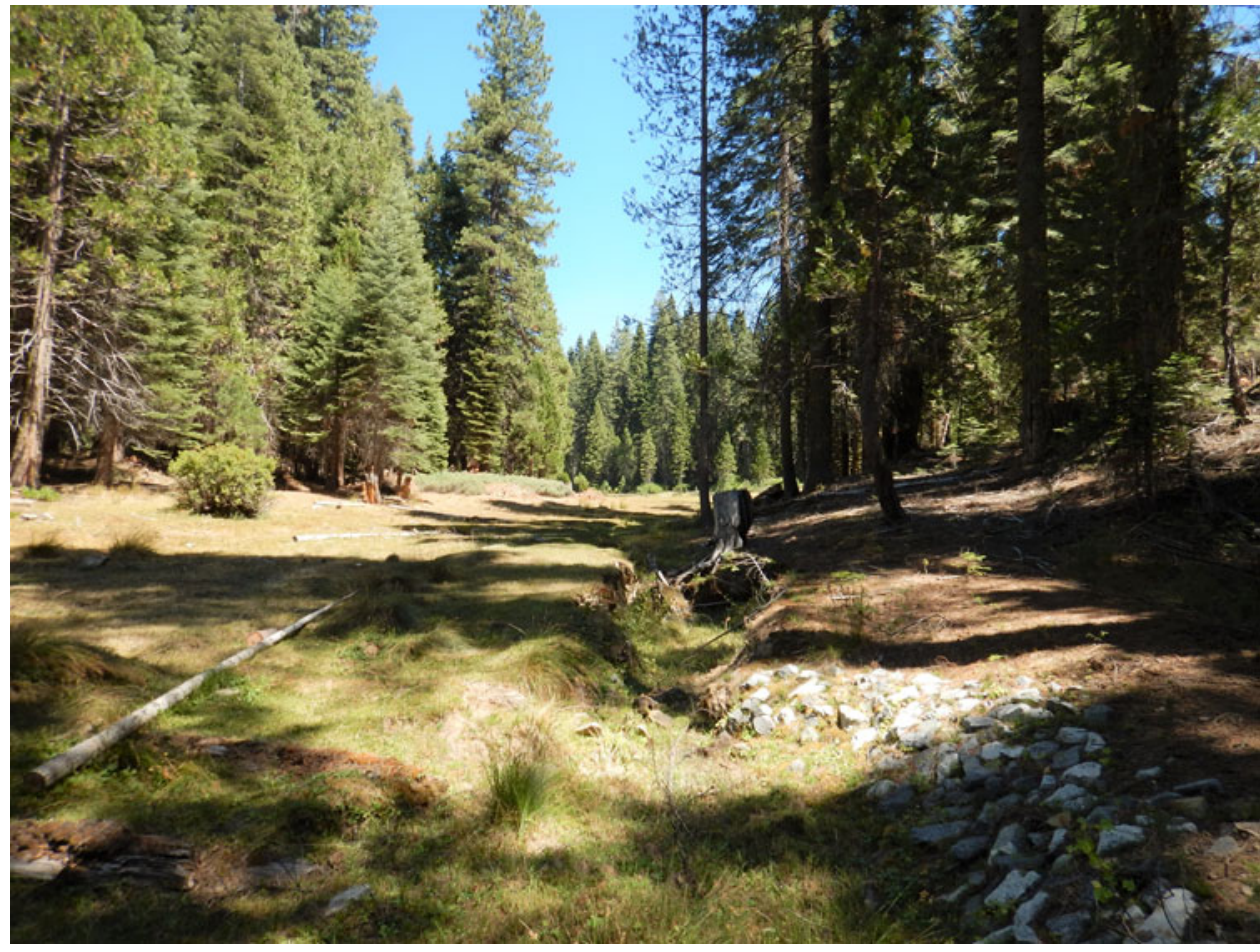

Fig. 2. A meadow on the Sierra National Forest that Forest Service staff had treated through placement of rocks to deter erosion. The North Fork Mono Tribe's vision of restoration incorporates cultural burning and thinning of the conifer trees that are shading out the meadow as well as treating the incised channels (photo by Jonathan W. Long).

encroachment, lack of fire, and other factors that contributed to the meadow degradation.

Meadow restoration projects on White Mountain Apache tribal lands have adapted traditional concepts in applying years of successive treatments to bring back water, plants, color, sounds, and other qualities that traditionally indicate rejuvenation (Fig. 3) (Long et al., 2003). For example, Mae Burnette describes the sounds of flowing water as being like speech, and an indicator of the health of a place. As part of spring restoration efforts, she has placed flat rocks to create small, babbling waterfalls below the springhead. Forest Service researchers and tribal staff and students have come to recognize that the splashing sound of small waterfalls in larger streams that were not naturally rocky could also be an indicator of vulnerability to erosion and other damaging effects; they have learned to modify the placement of riffle formations to ensure that such streams flow audibly but more gently (Medina \& Long, 2004).
The belief that springs are alive influenced other aspects of restoration. Mae Burnette designed fencing to include gates that facilitate access by humans and that also serve as an opening through which the springs could "breathe." She compares the concept to how native weavers leave openings in their designs and how Apaches traditionally leave the water basket ("tus") open to maintain the life force of the water it contains (Fig. 4). Subtleties of fence design go beyond a narrow focus of how to eliminate ovetrampling, since the construction will influence how people, animals, and flowing waters will respond to it. Showing thoughtfulness in the design of the fence indicates that the treatment was done respectfully, which signals that visitors should also show respect to the site and the restoration efforts.

\section{Holistic tribal mindsets and restoration ethics}

Traditional perspectives help not only to set restoration goals but also to inform the choice of methods. For example, at one site on White Mountain Apache tribal lands, an elder suggested using a diesel-powered backhoe to dig out a spring that had become covered with vegetative growth; she reasoned that such heavy equipment could be used respectfully in this setting to achieve the desired result. In other cases, tools do matter, as when Mae Burnette avoided placement of metal gabion baskets in favor of native rock and plant materials to restore incising stream channels below sacred springs; her approach was consistent with Apache cultural traditions of not leaving metal in ceremonial or sacred spaces such as sweat lodges and springs (Long, Burnette, \& Lupe, 2005). Similarly, tribal cultural burners often use drip torches, but they may also avoid that tool at sites to avoid risk of harm to subsequent gatherers (who might accidentally ingest the fuel residues) and to honor more traditional fire-ignition techniques.

By adopting strict methodologies to achieve objectives for making inferences, Western scientific studies or managers may tend to discount other values. As one example, tribal members of a field crew were challenged by a non-tribal supervisor when they deviated from 
TRADITIONAL PERSPECTIVES INFLUENCE RESTORATION

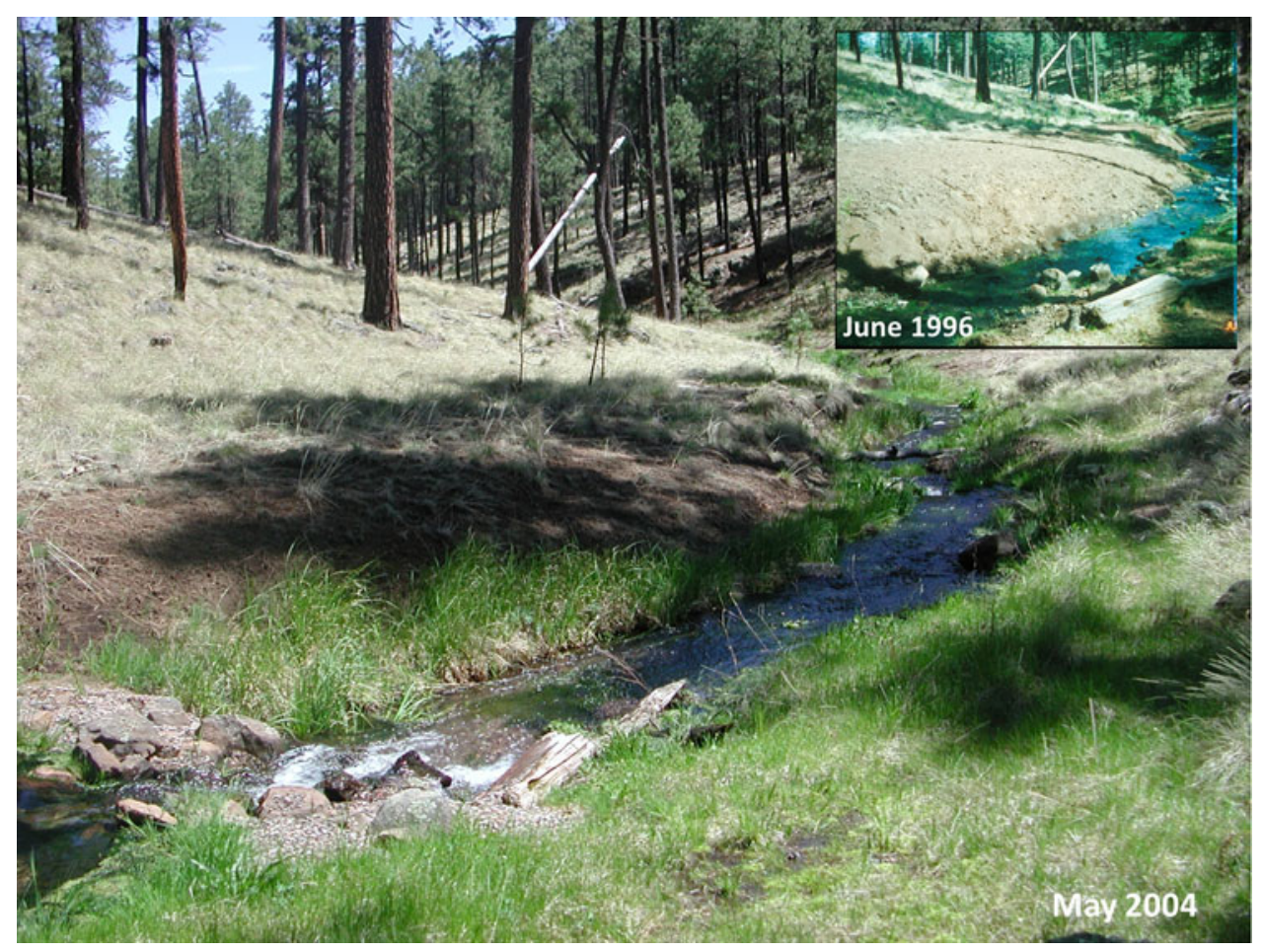

Fig. 3. At the Soldier Spring restoration site, the White Mountain Apache Tribe has conducted restoration treatments, including fencing, replanting of wetland vegetation, and placement of gravel and rock riffle formations (bottom left) (photo by Jonathan W. Long).

in deep reflection that allows for spiritual guidance. It is important for restoration efforts to be informed by local and traditional perspectives to promote connectedness rather than social conflict or harm (H. Fox \&t Cundill, 2018).

\section{Encouraging Consilient, Conscientious, and Consensual Restoration}

Restoration practitioners and theorists have embraced more holistic approaches to restoration that consider social as well as ecological objectives, especially through consideration of traditional knowledge (Higgs, 2005; Senos, Lake, Turner, \& Martinez, 2006). Academics have popularized the concepts of consilience and transdisciplinary science, which suggest that people can achieve deeper understandings by working across the boundaries and scale limitations of individual disciplines in natural sciences and humanities (Wilson, 1998). TEK has also been suggested as fertile ground for encouraging boundary-spanning scien-

a sampling plan to avoid disrupting a mother deer and her fawns at a site on a predetermined monitoring route. As a broader example, consider possible tensions over the principle in Western scientific frameworks of randomly assigning sites for treatment while leaving others as "controls." Traditional perspectives, on the other hand, may suggest that treatments are necessary to sustain living places. Consequently, withholding restoration treatments can raise concerns similar to those in a trial study involving human patients.

Another example of the importance of thinking broadly about system dynamics and ethics comes from a proposal to restore wetlands in North America by releasing new species of moths that would consume an invasive Eurasian variety of common reed. Some researchers have countered this proposal by noting how much many Native Americans value native reeds as well as other elements of these ecosystems that could be affected by such biological control methods (Kiviat et al., 2019). Such examples illustrate how challenging restoration can be in the complex and novel contexts of the modern era. Traditional teachings call upon practitioners to engage tific endeavors (Berkes, 2009; Pretty et al., 2009). Traditional perspectives suggest that restoration can be more conscientious by being careful, thoughtful, and vigilant regarding right and wrong. Restoration can also be more consensual by upholding the principle that tribes and other Indigenous communities should have "free, prior and informed consent" (Climate and Traditional Knowledges Workgroup, 2014; David-Chavez \&t Gavin, 2018).

Sometimes, the understanding that restoration goes beyond narrow ecological concerns becomes disturbingly clear. For example, severe erosion following a wildfire in Apache lands exposed a burial ground with ancient human remains and pottery (Fig. 5). The cutting by the stream revealed how "human" and "natural" elements had become interwoven over the centuries. However, the connections of tribes to ecosystems are often present in ways that are not so evident; for example, distinctive growth forms and markings on trees may indicate a history of cultural activity to experienced observers (Fig. 6). When physical signs of coevolution are not evident, land managers and scientists who are unfamiliar with cultural indicators 


\section{LONG ET AL.}

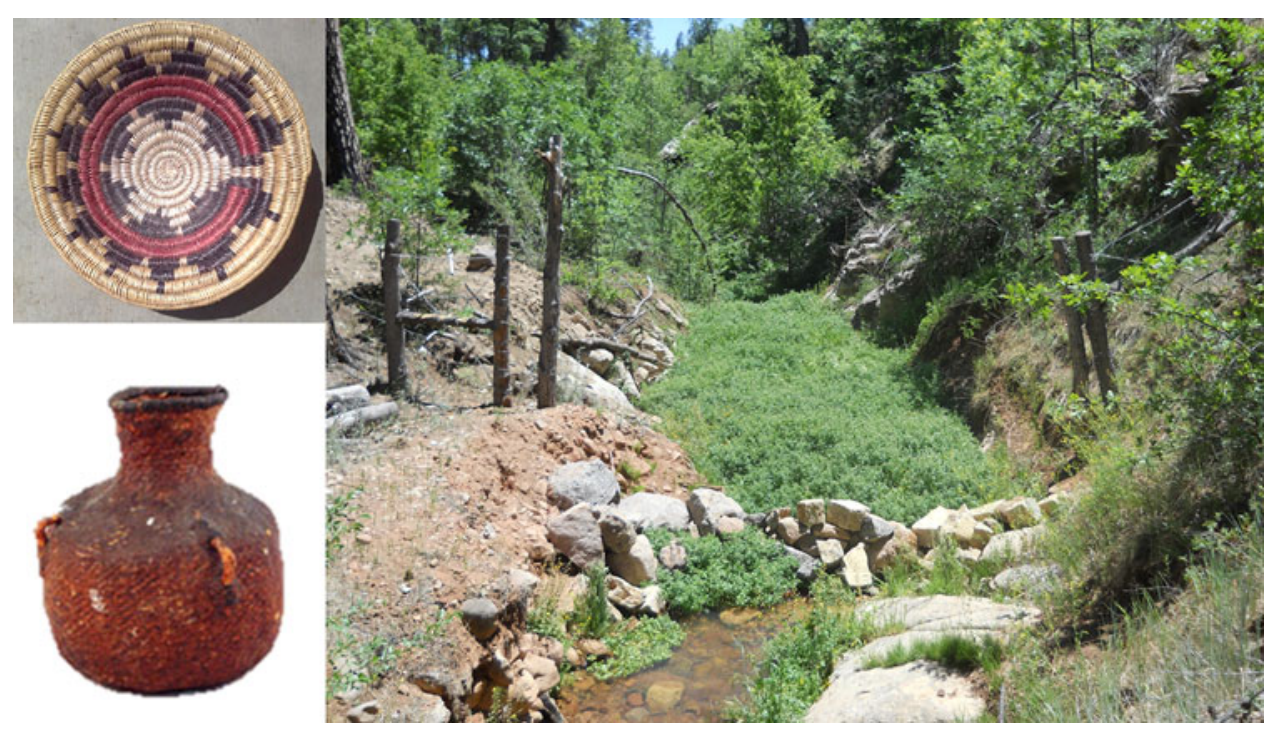

Fig. 4. A Navajo wedding basket, an Apache water jar (tus), and a fence being constructed around a culturally important spring all feature openings that represent breath and life (photo by Jonathan W. Long).

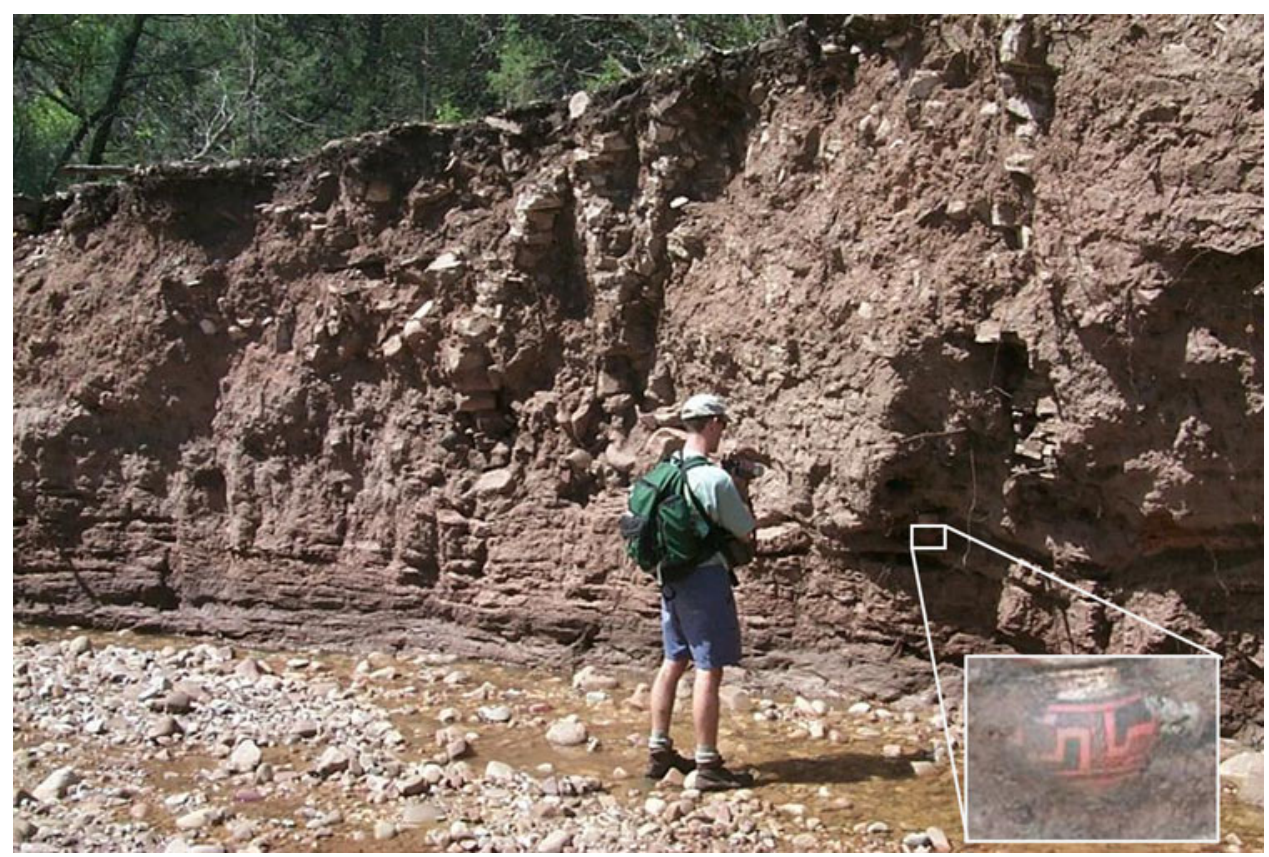

Fig. 5. Erosion following an unprecedented wildfire revealed how past human habitation (including a pot, inset) became conjoined with the stream ecosystem (photo by Arnold Pailzote). might underestimate the importance of community consensus and engagement. Ecosystem degradation has often impacted tribes in ways that can be difficult to see and unravel. For example, fire exclusion has led to declines in fire-dependent resources that limit the returns from attempts to harvest such resources; as a result, the knowledge of and apparent demand for such resources has also declined (Connors, 2000; Long \& Lake, 2018). While narrow ecological perspectives might overlook these relationships, the broad, holistic perspective informed by traditional knowledge can bring them back to the surface. Ethnoecologist Gary Nabhan has written that "Whether one sees the cultivation that human hands have done in a particular landscape depends to some extent on whether one looks for it and whether one is prepared to see it. 'Wilderness' is a concept that can incline one not to look, hence not to see" (Nabhan, 1995, p. 94). Indigenous perspectives help correct the distortions imparted by chauvinistic terms often used to describe places, such as "pre-settlement," "wild," "remote," "undeveloped," "pristine," and "virgin."

\section{Psychological and social effects}

Holistic perspectives may enhance the success of restoration by encouraging positive psychological and social effects that help sustain community restoration efforts. An early proponent of ecocultural restoration explained that it "closely parallels at a spiritual and emotional level what the restorationist seeks to achieve in the landscape itself," reflecting a core belief that healing people is connected to healing the land, and, reciprocally, healing the land is connected to healing people (RogersMartinez, 1992, p. 66). Traditional 
TRADITIONAL PERSPECTIVES INFLUENCE RESTORATION

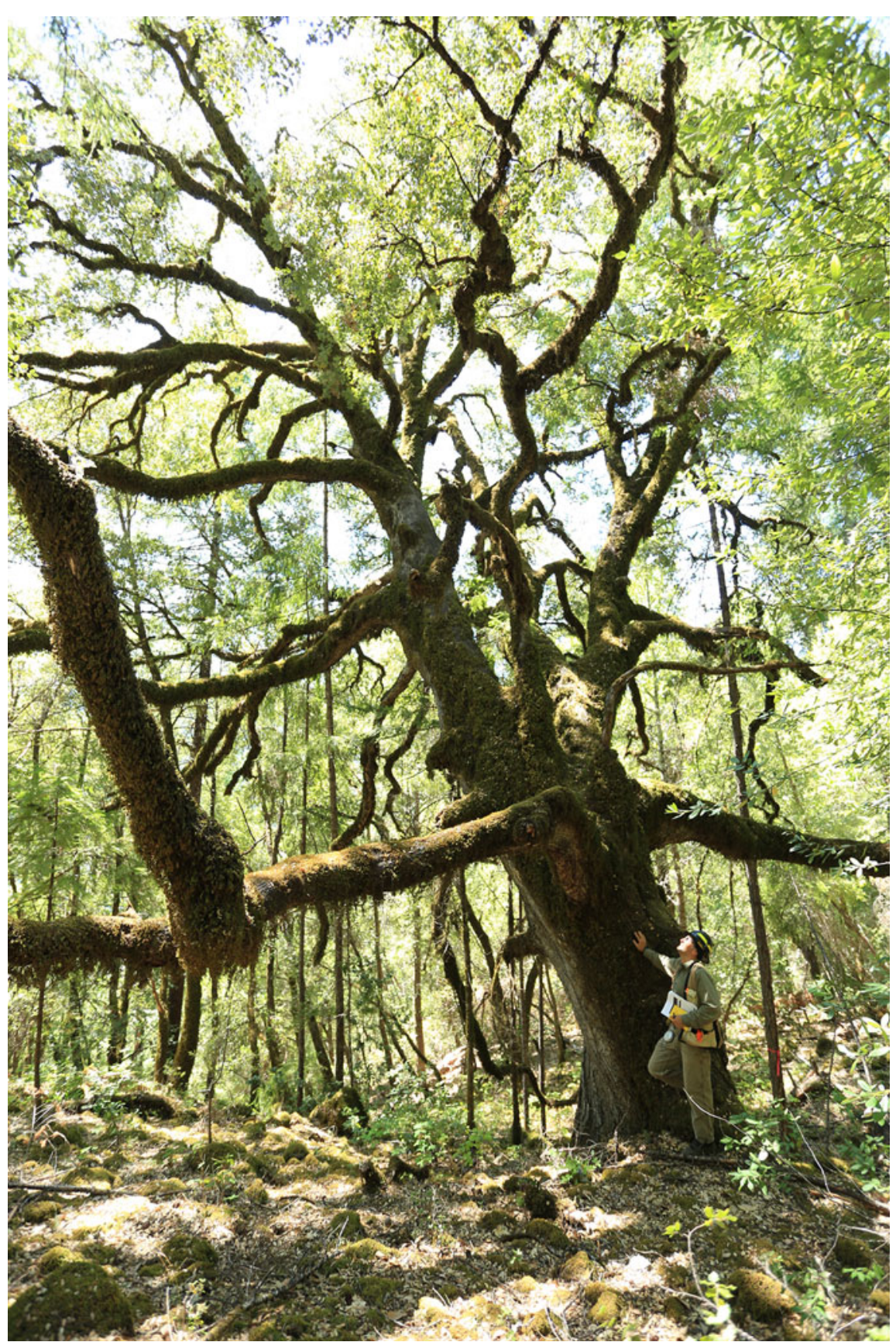

Fig. 6. An unusually large "legacy" canyon live oak tree has a distinctive architecture that indicates a history of past Native American habitation, careful burning, and tending (photo: Michael Hentz, Mid Klamath Watershed Council). perspectives conveyed through stories of the natural world have long served to cultivate "heightened mental capacity" (Basso, 1996, p. 130), specifically by reminding people of priorities and right behavior and helping them to deal with stresses and to think holistically, altruistically, and long-term. Another focus of a traditional perspective is the intergenerational transmission of knowledge from elders to youth. Reinforcing these traditions as part of restoration efforts may help reinforce positive actions, such as respecting fences, closing gates, picking up litter, and supporting reintroductions of extirpated species. Place names, rituals, songs, storytelling, and cultural practices can help put restoration efforts into this deeper cultural context. For example, a medicine person revived a traditional song of the wolf when that species was reintroduced into the lands of the White Mountain Apache Tribe.

Greater understanding of the connections between ancestral traditions and ecological outcomes could help both native and non-native communities to establish more mutualistic relationships with the lands upon which they depend. Many of our observations appear congruent with findings from a systematic review of restoration research that identified strategies to effectively engage local communities (H. Fox \& Cundill, 2018). Systematic review of projects that have engaged tribes might help reveal factors that yield more beneficial restoration. Such reviews could be facilitated if there were more structured reporting of collaborative restoration projects that engage tribes.

\section{Conclusion}

Traditional perspectives regard the natural world beyond plants and animals as rich with life force that requires moral considerations. A traditional perspective can help recognize dynamics that are often hidden to less experienced observers, such as how the architecture of a tree reveals a history of human engagement with the land. These histories and the capacity to perceive 


\section{LONG ET AL.}

them are in danger as both social and landscape memories are washed away, bulldozed, burned up, or buried. Restoration informed by traditional perspectives can reveal these patterns and help presentday tribal and non-tribal communities understand the need and opportunities for holistic restoration in the face of novel threats. Restoration depends on traditional perspectives to see the world more completely and with a fuller conscience.

\section{Author Note}

The findings and conclusions in this manuscript are those of the authors and should not be construed to represent any official determination or policy by the U.S. Government, U.S. Department of Agriculture, the White Mountain Apache Tribe, or the North Fork Mono Tribe.

\section{Acknowledgment}

We thank our many elders and colleagues who have contributed to our understandings of traditional knowledge and restoration.

\section{Author Disclosure Statement}

No competing financial interests exist.

\section{Funding Information}

Development of this article was supported in part by the U.S. Department of Agriculture, U.S. Forest Service.

\section{REFERENCES}

Aldern, J. D., \& Goode, R. W. (2014). The stories hold water: Learning and burning in North Fork Mono homelands. Decolonization: Indigeneity, Education \& Society, 3, 26-51.

Anderson, M. K. (2005). Tending the wild: Native American knowledge and the management of California's natural resources. Berkeley, CA: University of California Press.

Anderson, M. K. (2018). The use of fire by Native Americans in California. In J. W. van Wagtendonk, N. G. Sugihara, S. L. Stephens, A. E. Thode, K. E. Shaffer, \&t J. Fites-Kaufman (Eds.), Fire in California's ecosystems (2nd ed., pp. 381-398). Berkeley, CA: University of California Press.

Aronson, J., Blignaut, J. N., \& Aronson, T. B. (2017). Conceptual frameworks and references for landscape-scale restoration: Reflecting back and looking forward. Annals of the Missouri Botanical Garden, 102, 188-201.

Bang, M., \& Medin, D. (2010). Cultural processes in science education: Supporting the navigation of multiple epistemologies. Science Education, 94, 10081026.

Bang, M., Warren, B., Rosebery, A. S., \&t Medin, D. (2012). Desettling expectations in science education. Human Development, 55, 302-318.

Bash, J. S., \&t Ryan, C. M. (2002). Stream restoration and enhancement projects: Is anyone monitoring? Environmental Management, 29, 877-885.
Basso, K. H. (1996). Wisdom sits in places. Albuquerque, NM: University of New Mexico Press.

Berkes, F. (2009). Evolution of co-management: Role of knowledge generation, bridging organizations and social learning. Journal of Environmental Management, 90, 1692-1702.

Berkes, F., Colding, J., \& Folke, C. (2000). Rediscovery of traditional ecological knowledge as adaptive management. Ecological Applications, 10, 12511262.

Berkes, F., \& Turner, N. J. (2006). Knowledge, learning and the evolution of conservation practice for social-ecological system resilience. Human Ecology, 34, 479-494.

Cajete, G. (2000). Native science: Natural laws of interdependence. Santa Fe, NM: Clear Light Publishers.

Casagrande, D. G., \& Vasquez, M. (2009). Restoring for cultural-ecological sustainability in Arizona and Connecticut. In M. Hall (Ed.), Restoration and history: The search for a usable environmental past (pp. 195-209). New York, NY: Routledge Press.

Chisholm Hatfield, S., Marino, E., Whyte, K. P., Dello, K. D., \& Mote, P. W. (2018). Indian time: Time, seasonality, and culture in traditional ecological knowledge of climate change. Ecological Processes, 7, doi:10.1186/s13717-018-0136-6

Clewell, A. F., \& Aronson, J. (2006). Motivations for the restoration of ecosystems. Conservation Biology, 20, 420-428.

Climate and Traditional Knowledges Workgroup. (2014). Guidelines for considering traditional knowledges in climate change initiatives. Retrieved from https:// climatetkw.wordpress.com

Connors, S. M. (2000). Ecology and religion in Karuk orientations toward the land. In G. Harvey (Ed.), Indigenous religions (pp. 139-151). New York, NY: Cassell.

David, A. T., Asarian, J. E., \& Lake, F. K. (2018). Wildfire smoke cools summer river and stream water temperatures. Water Resources Research, 54, 72737290.

David-Chavez, D. M., \& Gavin, M. C. (2018). A global assessment of Indigenous community engagement in climate research. Environmental Research Letters, 13, doi:10.1088/1748-9326/aaf300

Deloria, V., \& Deloria, B. (1999). Spirit \& reason: The Vine Deloria, Jr., reader. Golden, CO: Fulcrum Publishing.

Eriksen, C., \& Hankins, D. L. (2014). The retention, revival, and subjugation of Indigenous fire knowledge through agency fire fighting in eastern Australia and California. Society \& Natural Resources, 27, 1288-1303.

Fox, C. A., Reo, N. J., Turner, D. A., Cook, J., Dituri, F., Fessell, B., ... Wilson, M. (2017). "The river is us; the river is in our veins": Re-defining river restoration in three Indigenous communities. Sustainability Science, 12, 521-533.

Fox, H., \& Cundill, G. (2018). Towards increased community-engaged ecological restoration: A review of current practice and future directions. Ecological Restoration, 36, 208-218.

Goode, R. W. (2013). Burning down to the village. Clovis, CA: Eagle Eye Enterprises, Inc.

Guerrero-Gatica, M., Aliste, E., \& Simonetti, J. A. (2019). Shifting gears for the use of the shifting baseline syndrome in ecological restoration. Sustainability, 11 doi:10.3390/su11051458

Halpern, A. A. (2016). Prescribed fire and tanoak (Notholithocarpus densifolius) associated cultural plant resources of the Karuk and Yurok people of California (PhD dissertation). University of California at Berkeley, Berkeley, CA. 
TRADITIONAL PERSPECTIVES INFLUENCE RESTORATION

Higgs, E. (2005). The two-culture problem: Ecological restoration and the integration of knowledge. Restoration Ecology, 13, 159-164.

Karuk Tribe. (2019). Karuk climate adaptation plan. Happy Camp, CA: Karuk Tribe. Kimmerer, R. W. (2013). Braiding sweetgrass: Indigenous wisdom, scientific knowledge and the teachings of plants. Minneapolis, MN: Milkweed Editions.

Kiviat, E., Meyerson, L. A., Mozdzer, T. J., Allen, W. J., Baldwin, A. H., Bhattarai, G. P., ... Cronin, J. T. (2019). Evidence does not support the targeting of cryptic invaders at the subspecies level using classical biological control: The example of Phragmites. Biological Invasions, 21, 2529-2541.

Klimaszewski-Patterson, A., \& Mensing, S. A. (2016). Multi-disciplinary approach to identifying Native American impacts on Late Holocene forest dynamics in the southern Sierra Nevada range, California, USA. Anthropocene, 15, $37-48$.

Lake, F. K., Parrotta, J., Giardina, C. P., Davidson-Hunt, I., \&t Uprety, Y. (2018). Integration of traditional and Western knowledge in forest landscape restoration. In S. Mansourian \& J. Parrotta (Eds.), Forest landscape restoration: Integrated approaches to support effective implementation (pp. 198-226). New York, NY: Routledge.

Long, J. W., Burnette, B. M., \&t Lupe, C. S. (2005). Fire and springs: Reestablishing the balance on the White Mountain Apache Reservation. In C. van Riper \& D. J. Mattson (Eds.), The Colorado Plateau II: Biophysical, socioeconomic, and cultural research (pp. 381-396). Tucson, AZ: University of Arizona Press.

Long, J. W., \&t Endfield, D. (2000). Restoration of White Springs. In P. F. Folliott, M. B. Baker, C. B. Edminster, B. Carleton, M. C. Dillon, \& K. C. Mora, (Eds.), Land stewardship in the 21st Century: The contributions of watershed management (Proc. RMRS P-13, pp. 359-360). Fort Collins, CO: U.S. Department of Agriculture, Forest Service Rocky Mountain Research Station.

Long, J. W., Goode, R. W., Gutteriez, R. J., Lackey, J. J., \&t Anderson, M. K. (2017). Managing California black oak for tribal ecocultural restoration. Journal of Forestry, 115, 426-434.

Long, J. W., \& Lake, F. K. (2018). Escaping a socioecological trap through tribal stewardship on national forest lands in the Pacific Northwest, USA. Ecology and Society, 23, doi:10.5751/ES-10041-230210

Long, J. W., Lake, F. K., Lynn, K., \& Viles, C. (2018). Tribal ecocultural resources and engagement. In T. Spies, P. Stine, R. Gravenmier, J. Long, \& M. Reilly (Eds.), Synthesis of science to inform land management within the Northwest Forest Plan area (Vol. 966, Gen. Tech. Rep. PNW-GTR-966, pp. 851-917). Portland, OR: USDA Forest Service, Pacific Northwest Research Station.

Long, J. W., Tecle, A., \& Burnette, B. (2003). Cultural foundations for ecological restoration on the White Mountain Apache Reservation. Conservation Ecology, 8, Article 4, 13 pp.

McGregor, D. (2005). Traditional ecological knowledge: an Anishnabe woman's perspective. Atlantis: Critical Studies in Gender, Culture \&t Social Justice, 29, 103-109.

Medina, A. L., \&t Long, J. W. (2004). Placing riffle formations to restore stream functions in a wet meadow. Ecological Restoration, 22, 120-125.

Nabhan, G. P. (1995). Cultural parallax in viewing North American habitats. In M. E. Soulé \&t G. Lease (Eds.), Reinventing nature? Responses to postmodern deconstruction (pp. 87-101). Washington DC: Island Press.

Pilsk, S., \& Cassa, J. C. (2005). The Western Apache home: Landscape management and failing ecosystems In G. J. Gottfried, B. S. Gebow, L. G. Eskew, \& C. B.
Edminster (Eds.), Connecting mountain islands and desert seas: Biodiversity and management of the Madrean Archipelago II (Vol. 36, Proc. RMRS-P-36, pp. 282-286). Fort Collins, CO: U.S. Department of Agriculture, Forest Service, Rocky Mountain Research Station.

Pretty, J., Adams, B., Berkes, F., de Athayde, S. F., Dudley, N., Hunn, E., ... Pilgrim, S. (2009). The intersections of biological diversity and cultural diversity: Towards integration. Conservation and Society, 7, 100-112.

Raymond, C. M., Singh, G. G., Benessaiah, K., Bernhardt, J. R., Levine, J., Nelson, H., ... Chan, K. M. (2013). Ecosystem services and beyond: Using multiple metaphors to understand human-environment relationships. Bioscience, 63, 536-546.

Rogers-Martinez, D. (1992). Northwestern coastal forests: The Sinkyone Intertribal Park project. Ecological Restoration, 10, 64-69.

Rossier, C., \& Lake, F. K. (2014). Indigenous traditional ecological knowledge in agroforestry (Vol. 14, Agroforestry Note 44). Lincoln, NE: US Department of Agriculture, Forest Service, Washington Office Research and Development.

Russo, L., Nichol, C., \& Shea, K. (2016). Pollinator floral provisioning by a plant invader: Quantifying beneficial effects of detrimental species. Diversity and Distributions, 22, 189-198.

Salmón, E. (2000). Kincentric ecology: Indigenous perceptions of the human-nature relationship. Ecological Applications, 10, 1327-1332.

Senos, R., Lake, F. K., Turner, N., \& Martinez, D. (2006). Traditional ecological knowledge and restoration practice in the Pacific Northwest. In D. Apostol \& M. Sinclair (Eds.), Restoring the Pacific Northwest: The art and science of ecological restoration in Cascadia (pp. 393-426). Washington, DC: Island Press.

Silko, L. M. (1987). Landscape, history, and the Pueblo imagination. In D. Halpern (Ed.), On nature: Nature, landscape, and natural history (pp. 83-94). San Francisco, CA: North Point.

Society for Ecological Restoration International Science \& Policy Working Group. (2004). The SER international primer on ecological restoration. Tucson, AZ: Society for Ecological Restoration.

Spies, T. A., Long, J. W., Charnley, S., Hessburg, P. F., Marcot, B. G., Reeves, G. H., ... Raphael, M. G. (2019). Twenty-five years of the Northwest Forest Plan: What have we learned? Frontiers in Ecology and the Environment, 17, 511-520.

Swanston, C. W., Janowiak, M. K., Brandt, L. A., Butler, P. R., Handler, S. D., Shannon, P. D., ... St. Pierre, M. (2016). Forest adaptation resources: Climate change tools and approaches for land managers (Gen. Tech. Rep. NRS-GTR-87-2). Newtown Square, PA: USDA Forest Service, Northern Research Station.

Terence, M. (2016, November 3). Unleashing the TREX: Why officials think controlled burns can save California from wildfire. North Coast Journal of Politics, People and Art. Retrieved from https://www.northcoastjournal.com/humboldt/ unleashing-the-trex/Content?oid $=4132514$

Thompson, C. M., \& Purcell, K. L. (2016). Conditions inside fisher dens during prescribed fires; what is the risk posed by spring underburns? Forest Ecology and Management, 359, 156-161.

Tomblin, D. (2010). American Indian restoration. In M. Hall (Ed.), Restoration and history: The search for a usable environmental past (pp. 355-371). New York, NY: Routledge.

Tribal Adaptation Menu Team. (2019). Dibaginjigaadeg anishinaabe ezhitwaad: a tribal climate adaptation menu. Odanah, WI: Great Lakes Indian Fish and Wildife Commission. 


\section{LONG ET AL.}

USDA Forest Service. (2015). Forest Service research and development: Tribal engagement roadmap (FS-1043). Washington, DC: USDA Forest Service. Retrieved from https://www.fs.fed.us/climatechange/pdf/roadmap.pdf

Willette, M., Norgaard, K., Reed, R., \&t Tribe, K. (2015). You got to have fish: Families, environmental decline and cultural reproduction. Families, Relationships and Societies, 5, 375-392.

Wilson, E. O. (1998). Consilience among the great branches of learning. Daedalus, $127,131-149$

Winthrop, R. H. (2014). The strange case of cultural services: Limits of the ecosystem services paradigm. Ecological Economics, 108, 208-214.

Yurok Tribe. (2019). Yurok Tribe condor program. Retrieved from http://www.yurok tribe.org/departments/selfgovern/wildlife_program/condor/condorproject.htm
Address correspondence to:

Jonathan W. Long

USDA Forest Service Pacific Southwest Research Station

1731 Research Park Dr.

Davis, CA 95618

USA

E-mail: jonathan.w.long@usda.gov

Received: October 1, 2019 Accepted: November 29, 2019 